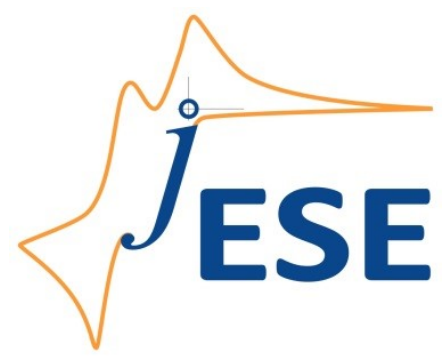

Open Access: ISSN 1847-9286

www.jESE-online.org

Original scientific paper

\title{
Electrochemical analysis of indigo carmine using polyarginine modified carbon paste electrode
}

\author{
D’Souza S. Edwin ${ }^{1,2}$, Jamballi G. Manjunatha ${ }^{1, ه}$, Chenthattil Raril ${ }^{1}$, Tigari Girish ${ }^{1}$, \\ Doddarasinakere K. Ravishankar ${ }^{3}$ and Huligerepura J. Arpitha ${ }^{4}$ \\ ${ }^{1}$ Department of chemistry, FMKMC College, Madikeri, Constituent College of Mangalore University, \\ Karnataka, India \\ ${ }^{2}$ Department of Chemistry, St. Philomena College, Puttur, Karnataka, India \\ ${ }^{3}$ Department of Chemistry, Sri. Mahadeshwara Govt. First Grade College, Kollegal, \\ Chamarajanagar, Karnataka, India \\ ${ }^{4}$ Department of Physics, Sri Adichunchanagiri First Grade College, Channarayapatna, India
}

Corresponding author: ${ }^{凶}$ manju1853@gmail.com; Tel.: +91- 08272228334

Received: January 13, 2021; Revised: March 18, 2021; Accepted: March 29, 2021

\begin{abstract}
Suitable electrocatalytic method is established for the selective determination of indigo carmine (IC) at polyarginine modified carbon paste electrode (PAMCPE). Surface morphological study of bare carbon paste electrode (CPE) and PAMPCE is done by field emission scanning electron microscopy (FESEM). The influence of different parameters such as IC concentration, solution $\mathrm{pH}$ and potential scan rate on the electrode responses is studied using cyclic and differential pulse voltammetry techniques. The prepared PAMCPE shows better electrochemical response towards IC than CPE. No interference is noticed at simultaneous presence of IC and riboflavin (RF) in the solution. The electrocatalytic current of IC at PAMPCE is varied linearly with its concentration in two separate ranges, from $2 \times 10^{-7}$ to $10^{-6} \mathrm{M}$, and $1.5 \times 10^{-6}$ to $3.5 \times 10^{-6} \mathrm{M}$. Limits of detection (LOD) and quantification (LOQ) are determined as $2.53 \times 10^{-8}$ and $8.43 \times 10^{-8} \mathrm{M}$, respectively. The developed PAMCPE is showing successful reproducibility and stability. It is also found sensitive and reliable for trace amounts of IC in some real water and food samples. Since preparation of PAMCPE sensor is simple and easy, it could become a part of the standard method for determination of IC in real samples.
\end{abstract}

\section{Keywords}

Carbon paste; electropolymerization; food dye; real samples; cyclic voltammetry; differential pulse voltammetry 


\section{Introduction}

Dyes are the colored compounds of either synthetic or natural origin. Synthetic dyes are used in various industries like printing textiles, paint, cosmetics, pulp, and even in food industry [1]. Their degradation products are highly poisonous and dangerous to all living beings [2]. Indigo carmine (IC) $\left(5,5^{\prime}\right.$ indigodisulphonic acid sodium salt) is one such dyes used in cosmetic industry [3], food industry and in coloring of polyester fibers [4,5]. It is toxic in nature and can cause diarrhea and vomiting in human beings [6]. In analytical chemistry IC is used as redox indicator [7], food colorant, and in biology as microscopic stain [8]. The textile industry releases waste-water containing significant amounts of non-biodegradable dyes $[9,10]$. These dyes are carcinogenic and their removal from the industrial effluents is of the major environmental concern [11]. IC is also utilized in medical diagnosis apart from its use as an additive in pharmaceutical tablets and capsules [12]. Presence of IC in environment and real samples has to be traced, because IC ingestion can affect the liver, central nervous system, kidneys and eyes $[13,14]$. Therefore, it is proposed obligatory to identify the concentration of IC in a variety of natural samples. Hence, a susceptible and selective procedure for determination of IC would be of immense significance.

Variety of investigative methods have been selected for the identification of synthetic dyes, such as high-performance liquid chromatography with UV-Vis, spectrophotometry, stripping voltammetry capillary electrophoresis, UV-DAD or MS detectors [15-19]. Recently, the cyclic voltammetric technique was introduced for procuring information regarding the electrochemical reactions qualitatively and quantitatively. CV provides a lot of information concerning thermodynamics and kinetics of redox reactions [20-25]. Different electrodes were already applied to explore the performance of IC [26-27]. Among them, carbon paste electrode in its unmodified or modified form is frequently used to establish the performance of several chemical compounds, including electrochemical behavior of IC [28-30].

The purpose of this work is to deploy a better and easier voltammetric method for the assessment of IC. By using polymer modified carbon paste electrode, a direct, perceptive, prompt and entirely validated method, based on the voltametric response and oxidation mechanism of IC is intended to be derived. The oxidation mechanism of IC is shown in scheme 1.
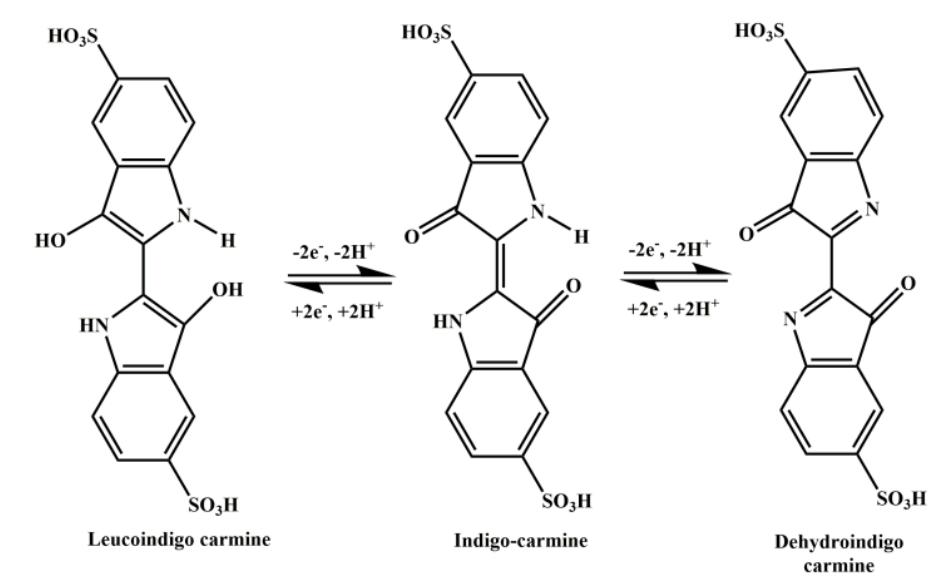

Scheme 1. Structure and oxidation reaction mechanism of IC

\section{Experimental}

Reagents

Arginine and indigo carmine were purchased from Molychem, Mumbai, India. Graphite ( 150 mesh, loss on drying $=0.5 \%$ at $120^{\circ} \mathrm{C}$, residue on ignition $=1 \%$ at $800{ }^{\circ} \mathrm{C}$ ), monosodium 
dihydrogen phosphate, disodium hydrogen phosphate, silicone oil (kinematic viscosity $=1000 \mathrm{cS}$, refractive index $=1.4035$ ) were obtained from Nice Chemicals, Cochin, India. Stock solution of IC $\left(25 \times 10^{-5} \mathrm{M}\right)$ and arginine $\left(25 \times 10^{-3} \mathrm{M}\right)$ were made ready in double distilled water. Standard solutions of $0.1 \mathrm{M}$ monosodium dihydrogen phosphate and $0.1 \mathrm{M}$ disodium hydrogen phosphate were mixed in intended proportion to get $0.1 \mathrm{M}$ phosphate buffer solution (PBS).

\section{Instrumentation}

Electrochemical analyzer CHI-6038E (USA) was used to perform all electrochemical experiments. Electrochemical cell was the three - electrode system, equipped with either CPE or PAMCPE as the working electrode, platinum wire as the auxiliary electrode, and standard calomel electrode (SCE) as the reference electrode. Field emission scanning electron microscopy (FESEM) from DST - PURSE Laboratory, Mangalore University, was used to investigate morphology of electrode surfaces. All measurements were done at the laboratory temperature.

Preparation of bare carbon paste electrode (CPE)

Carbon paste was developed by mixing the graphite powder and a binder (silicone oil) in the proportion of 60:40 (w/w) using a mortar and pestle, until a consistent paste is formed. A segment of the paste was crammed firmly into the cavity of a Teflon tube having $3 \mathrm{~mm}$ inner diameter. The electrode surface was polished using a tissue paper to get a smoother surface. The electrical contact was established by connecting a copper wire to the paste end of the tube. The electrode surface of thus formed carbon paste electrode (CPE) was revived for every measurement.

The surface of CPE was modified by polyarginine forming PAMCPE, which was prepared according to the electrochemical polymerization procedure described below.

\section{Results and discussion}

\section{Preparation of polyarginine modified carbon paste electrode}

Arginine solution of $10^{-3} \mathrm{M}$ was placed in electrochemical cell containing $0.1 \mathrm{M}$ PBS of $\mathrm{pH}$ 5.7. The polymer film on CPE was developed by electrochemical polymerization of arginine using cyclic voltammetry in the potential range from -0.25 to $1.5 \mathrm{~V}$, for 10 cycles at the sweep rate of $0.1 \mathrm{~V} \mathrm{~s}^{-1}$. The cyclic voltammograms produced are presented in Figure 1. Prior further experiments, the formed polyarginine modified electrode (PAMCPE) was rinsed with distilled water to remove the unreacted monomer.

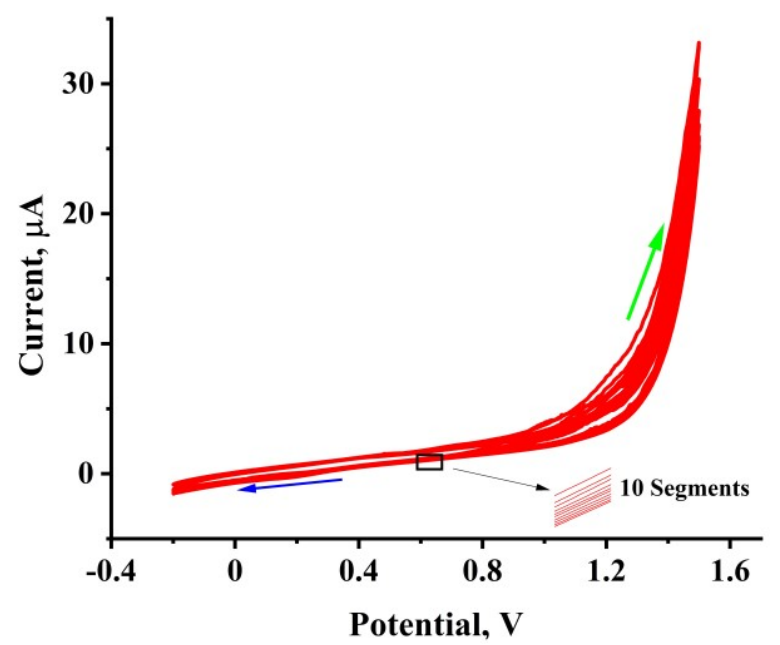

Figure 1. CVs of electrochemical polymerization of $10^{-3} \mathrm{M}$ arginine on CPE in $0.1 \mathrm{MPBS}$, $\mathrm{pH} 5.7$, in 10 cycles with sweep rate $0.1 \mathrm{~V} \mathrm{~s}^{-1}$ 


\section{Surface characterization of CPE and PAMCPE}

The surface morphological investigations of CPE and PAMCPE were assessed by Field emission scanning electron microscopy (FESEM). In Figure 2, the surface morphological examination outcomes of bare (Figure 1a) and polymer modified electrode (Figure 1b) are indicated. The image of CPE shows an irregular arrangement of graphite layers on its surface, whereas the image of PAMCPE is more compact and contains more uniform arrangement of graphite layers on its surface, which is due to presence of deposited polyarginine. It may be concluded that bare and polymer modified electrodes possess rather different surface morphology, what might have some influence on their electrochemical responses.

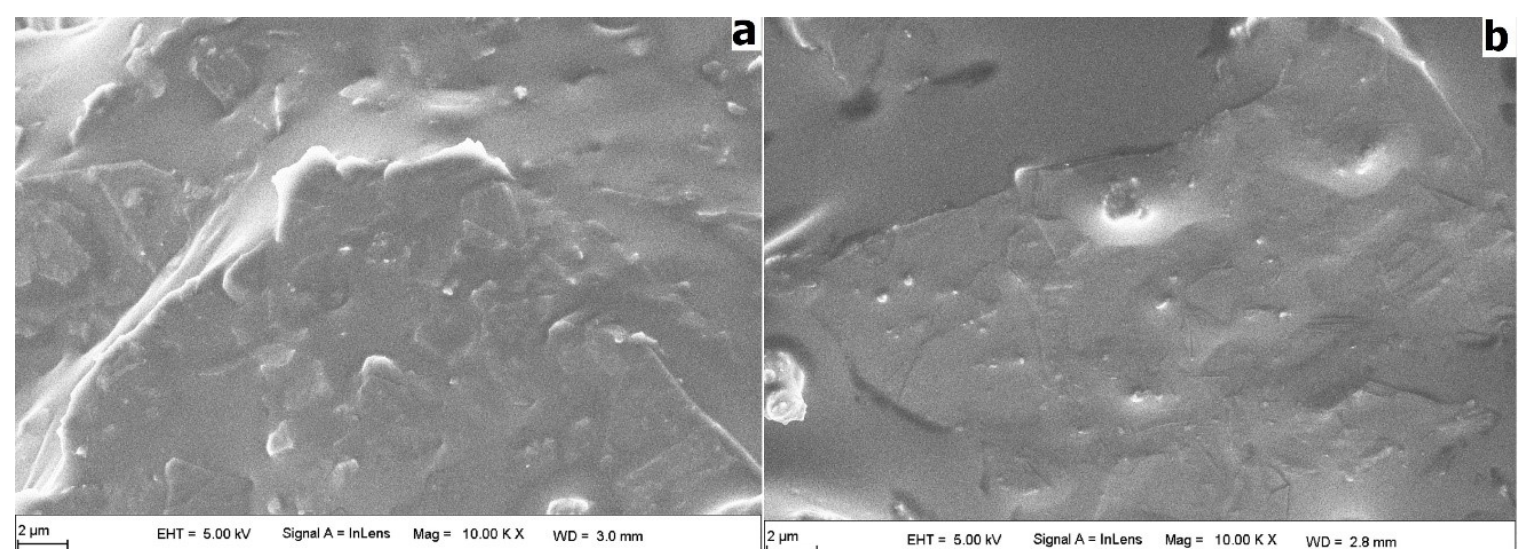

Figure 2. FESEM images of (a) CPE and (b) PAMCPE

\section{Electrochemical behavior of IC}

The electrochemical activity of IC at both electrodes was investigated through cyclic voltammetry (CV) and differential pulse voltammetry (DPV) techniques in $0.1 \mathrm{MPBS}, \mathrm{pH}$ 6.0. Differential pulse and cyclic voltammograms recorded for $10^{-5} \mathrm{M} \mathrm{IC}$ during the scrutiny of CPE and PAMCPE are represented in Figure 3. Figure $3 \mathrm{~A}$ exhibits oxidation peaks attained during DPV investigation of IC activity at CPE and PAMCPE. In the potential range from 0.25 to $0.50 \mathrm{~V}$, well defined peaks are detected for both electrodes, but the peak current response detected for the polymer modified carbon paste electrode is larger than the current of the bare electrode. Enhanced peak current and shift of anodic peak potential $E_{\mathrm{pa}}$ towards less positive value, suggest some electrocatalytic action of PAMCPE surface to IC oxidation.
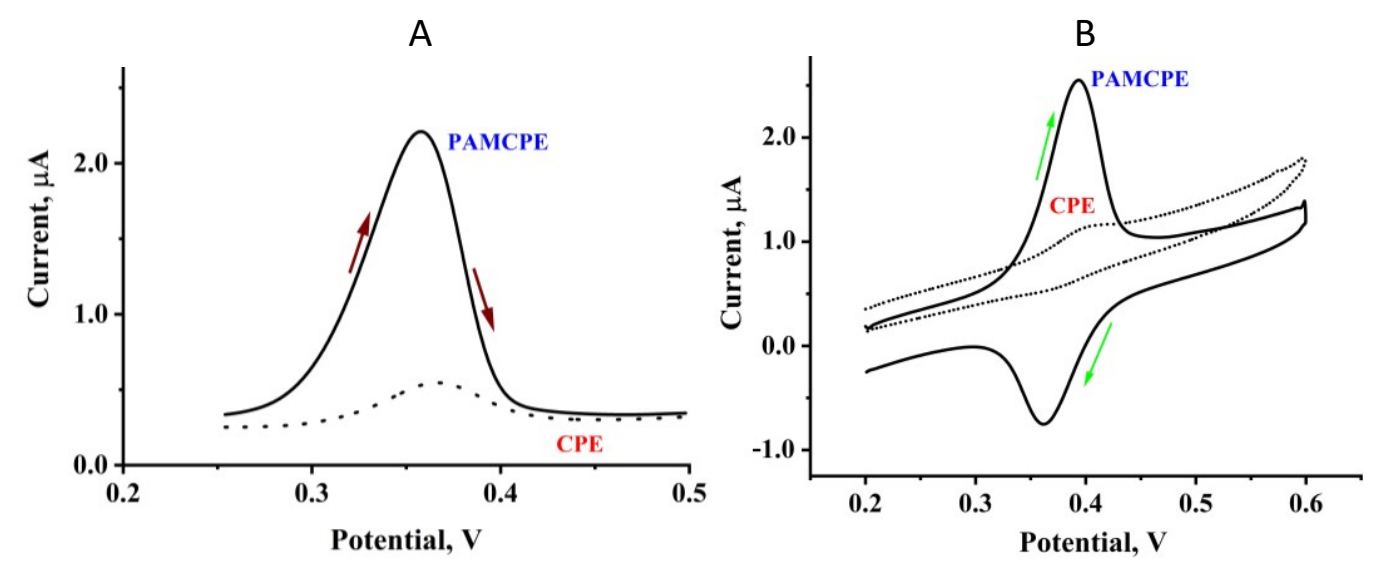

Figure 3. Redox activity of $10^{-5} \mathrm{M} I \mathrm{C}$ at CPE and PAMCPE in $0.1 \mathrm{M} P B S, p H 6.0$, recorded by:

(A) DPV at $0.05 \mathrm{Vs}^{-1}$ and (B) CV at $0.1 \mathrm{~V} \mathrm{~s}^{-1}$ 
$\mathrm{CV}$ responses of $\mathrm{IC}$ at $\mathrm{CPE}$ and PAMCPE are represented in Figure 3B. Within the potential from 0.20 to $0.60 \mathrm{~V}$, small redox peaks are observed for CPE at about $0.4 \mathrm{~V}$. For PAMCPE, however, sensitive and distinct oxidation and reduction peaks appear at 0.394 and $0.361 \mathrm{~V}$, respectively. Difference in these two peak potential values, $\Delta E_{p}=0.33 \mathrm{~V}$, indicates that the redox process of IC is reversible in nature, involving transfer of two electrons (Scheme 1).

\section{Effect of solution $\mathrm{pH}$}

The role of electrolyte $\mathrm{pH}$ on the oxidation of $10^{-5} \mathrm{M}$ IC at PAMCPE in $0.1 \mathrm{M}$ buffer solution was examined by $\mathrm{CV}$ technique at the scan rate of $0.1 \mathrm{Vs}^{-1}$. Influence of variation of $\mathrm{pH}$ in the range from 5.5 to 8.0 upon anodic peak currents of CVs is indicated in Figure $4 \mathrm{~A}$. The highest oxidation peak of IC is observed at $\mathrm{pH} 6.0$, being more or less reduced at other $\mathrm{pH}$ values. Therefore, in continuation of this study, pH 6.0 was chosen for further experiments with IC analyte.

The relation between the oxidation potential $\left(E_{\mathrm{pa}}\right)$ and $\mathrm{pH}$ of the solution is shown in Figure $4 \mathrm{~B}$. From the distinct linear part formed between $\mathrm{pH} 5.5$ to 7.0, the linear regression equation $\underline{E}_{\mathrm{pa}} / \mathrm{V}=0.56-0.029 \mathrm{pH}(R=0.99)$ was derived. If the linearity, however, was presumed for the whole $\mathrm{pH}$ range (5.5-8.0), the linear regression relationship is defined as $E_{\mathrm{pa}} / \mathrm{V}=0.71526-0.053 \mathrm{pH}$, but with lower squared correlation $(R=0.958)$. The obtained slope of $0.053 \mathrm{~V} \mathrm{pH}^{-1}$ is extremely close to the theoretical value of $0.058 \mathrm{~V} \mathrm{pH}^{-1}$, characteristic for equal number of electrons and protons in the redox process, what is in accordance with scheme 1 . By presenting $I_{\text {pa }}$ values $v s$. $\mathrm{pH}$ in Figure $4 \mathrm{C}$, it is suggested again that $\mathrm{pH} 6.0$ is the most constructive for the efficient and reliable determination of IC.
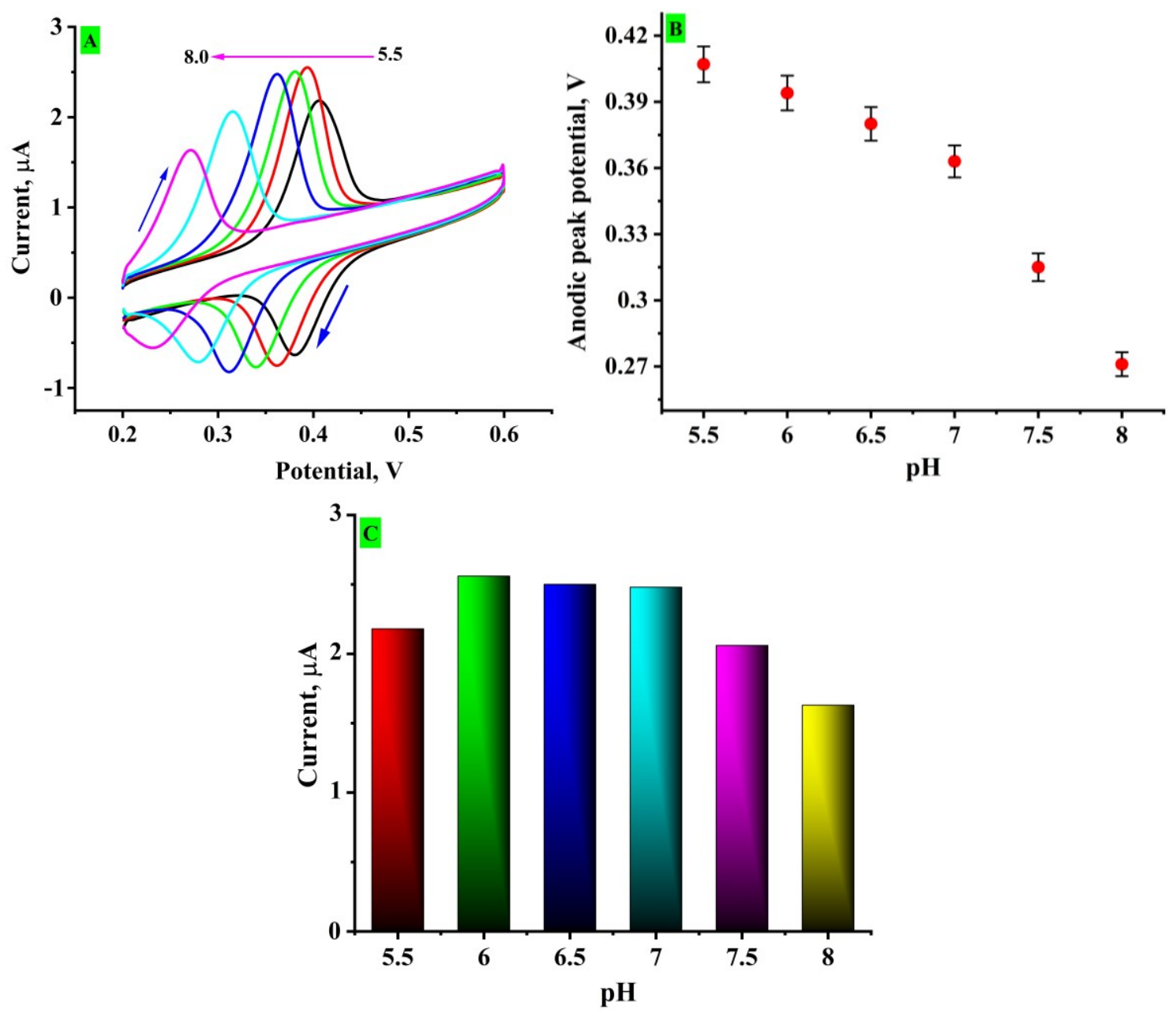

Figure 4. $(A) C V s\left(0.1 \mathrm{~V} \mathrm{~s}^{-1}\right)$ of $I C\left(10^{-5} \mathrm{M}\right)$ at PAMCPE in $0.1 \mathrm{M}$ PBS of different $p H$ values (5.5-8.0) (B) $\mathrm{E}_{p a}$ vs. $p H$; (C) I $I_{p a}$ vs. $p H$ 


\section{Effect of scan rate}

A lot of information concerning the electrochemical process of analyte at an electrode surface can generally be derived from the relation between peak current and scan rate in CVs. The electrochemical reaction of $10^{-5} \mathrm{M} I \mathrm{C}$ at PAMCPE was followed at variable scan rates $(0.1,0.125$, $0.150,0.175,0.200$, and $0.250 \mathrm{~V} \mathrm{~s}^{-1}$ ), and the obtained cyclic voltammograms are revealed in Figure $5 \mathrm{~A}$. Figure $5 \mathrm{~B}$ shows the linear relation obtained when $I_{\mathrm{pa}}$ is presented against the scan rate The linear regression equation, $I_{\mathrm{pa}} / \mu \mathrm{A}=1.15571+13.25714 \mathrm{v} / \mathrm{V} \mathrm{s}^{-1}(R=0.998)$, was developed for the scan rate range of 0.1 to $0.250 \mathrm{~V} \mathrm{~s}^{-1}$. Such linear relation between $I_{\mathrm{pa}}$ and $v$ reveals that the reaction of IC happening at PAMCPE is the adsorption restrained process.
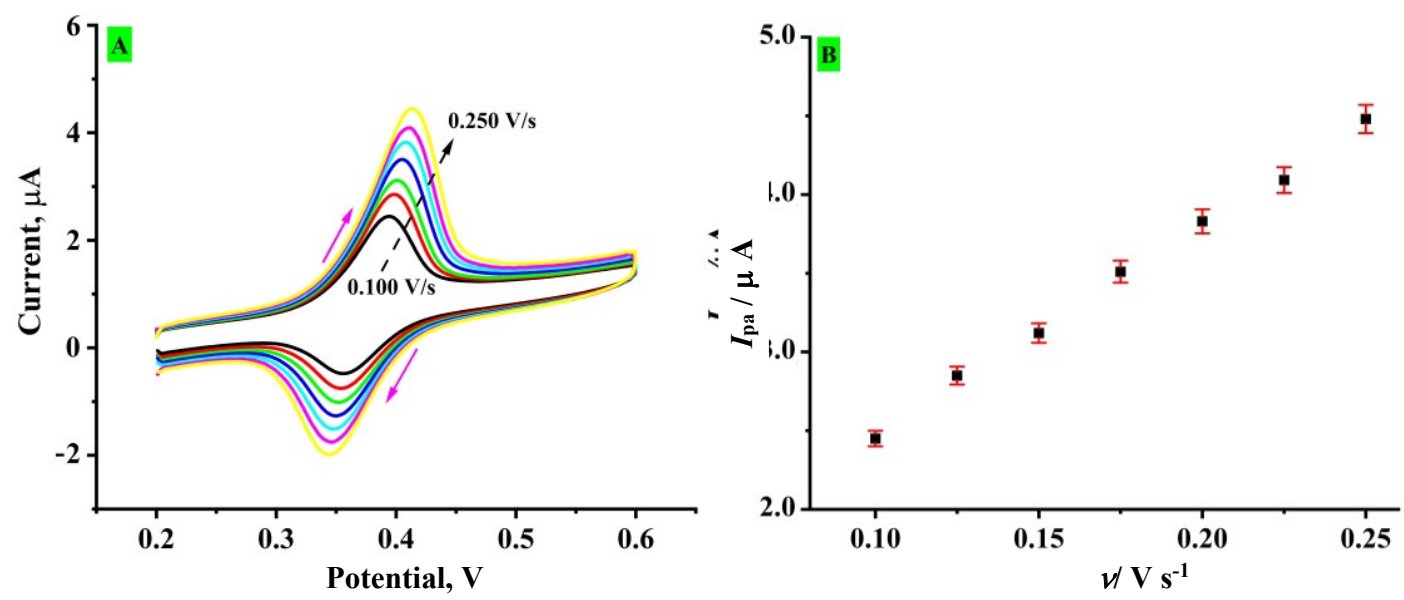

Figure 5. (A) CVs of IC $\left(10^{-5} \mathrm{M}\right)$ at PAMCPE in $0.1 \mathrm{M} P B S, \mathrm{pH} 6.0$ at different scan rates $\left(0.1-0.250 \mathrm{~V} \mathrm{~s}^{-1}\right)$; (B) anodic peak current vs. scan rate

\section{Simultaneous determination of IC and RF}

The electrochemical behavior of IC that is present along with RF in PBS solution, was examined by means of DPV. Possible interference of two substances and a capability for separate determinations of IC and RF at both electrodes were examined. Figure 6 shows DPVs of PAMCPE and CPE in the solution mixture containing IC $\left(10^{-5} \mathrm{M}\right)$ and $\mathrm{RF}\left(10^{-4} \mathrm{M}\right)$ in $0.1 \mathrm{M}$ PBS, $\mathrm{pH}$ 6.0. Two separate distinct peaks with much higher current responses are obtained the polymer modified electrode compared to bare electrode. It is obvious that PAMCPE enables separate estimation of two analytes without any major interference between them.

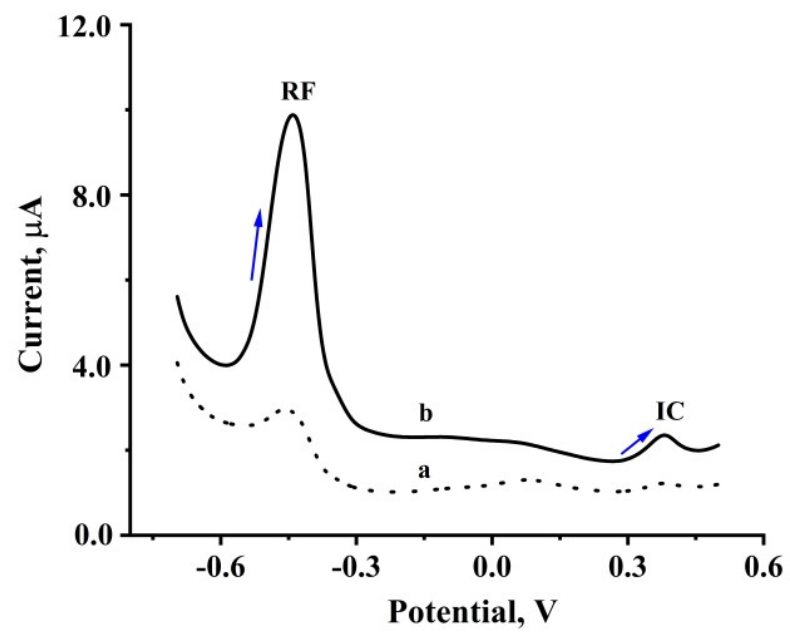

Figure 6. DPVs $\left(0.05 \mathrm{Vs}^{-1}\right)$ of the solution containing IC $\left(10^{-5} \mathrm{M}\right)$ and $R F\left(10^{-4} \mathrm{M}\right)$ in $0.1 \mathrm{MPBS}$, pH 6.0 at CPE (curve a) and PAMCPE (curve b) 


\section{Calibration curve and detection limit}

The correlation of the oxidation peak current value with IC concentration was investigated through DPV at $0.05 \mathrm{~V} / \mathrm{s}$, and the result of this investigation is plotted in Figure 7 . The oxidation peak current value presented versus IC concentration gives two linear segments, from $2 \times 10^{-7}$ to $10^{-6} \mathrm{M}$ (green line) and $1.5 \times 10^{-6} \mathrm{M}$ to $3.5 \times 10^{-6} \mathrm{M}$ (red line), respectively. Corresponding linear regression equations are: $I_{\mathrm{pa}} / \mu \mathrm{A}=4.886 \times 10^{-7}+1.413 C_{\mathrm{IC}} / \mathrm{M}(R=0.9952)$ and $I_{\mathrm{pa}} / \mu \mathrm{A}=1.56 \times 10^{-6}+0.106 C_{\mathrm{IC}} / \mathrm{M}$ $(R=0.9952)$. Here, the first linear segment from $2 \times 10^{-7}$ to $10^{-6} \mathrm{M}$ was considered for determination of limit of detection (LOD) and limit of quantification (LOQ). LOD and LOQ values were calculated from respective relations $3 \sigma / \mathrm{m}$ and $10 \sigma / \mathrm{m}$ [31], where $\sigma$ is the standard deviation obtained by 5 DPV measurements in blank solution (buffer without analyte) and $m$ is slope of the calibration curve. The calculated values of $L O Q$ and LOD for IC at PAMCPE are $8.43 \times 10^{-8}$ and $2.53 \times 10^{-8} \mathrm{M}$, respectively.

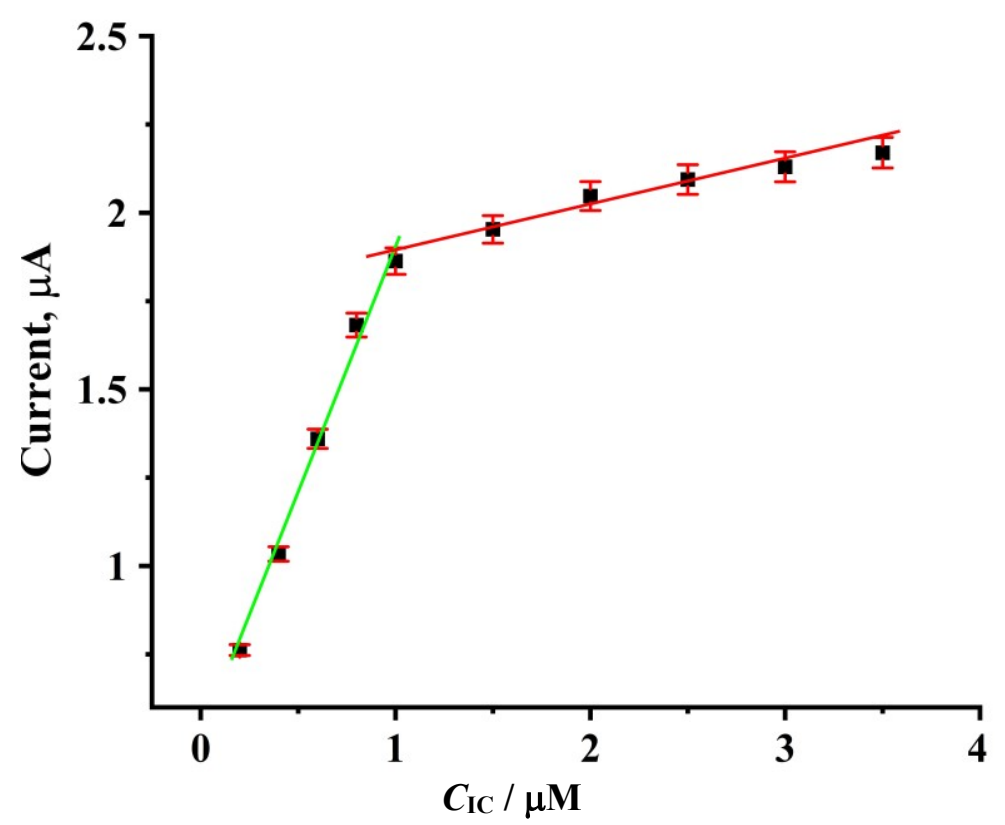

Figure 7. Calibration plot for determination of IC at PAMCPE in $0.1 \mathrm{MPBS}, \mathrm{pH} 6.0$ at $0.05 \mathrm{~V} \mathrm{~s}^{-1}$

In Table 1, the obtained detection limit and linear range of calibration plot for determination of IC at PAMCPE are compared with corresponding data taken from some related literature works [3236].

Table 1. Comparison of linear range and limit of detection for determination of IC produced by DPV at PAMCPE with literature data on some other techniques

\begin{tabular}{lccc}
\hline Technique & Linear range of concentration, molL $^{-1}$ & LOD, molL $^{-1}$ & Reference \\
\hline Resonance Rayleigh scattering & $2 \times 10^{-6}-32 \times 10^{-6}$ & $2.4 \times 10^{-8}$ & {$[32]$} \\
\hline Spectrophotometry & $1.7 \times 10^{-6}-39 \times 10^{-6}$ & $2.5 \times 10^{-8}$ & {$[33]$} \\
\hline Cyclic voltammetry & $2 \times 10^{-6}-6 \times 10^{-5}$ & $1.1 \times 10^{-7}$ & {$[34]$} \\
\hline Cyclic voltammetry & $8 \times 10^{-6}-1.3 \times 10^{-4}$ & $2.7 \times 10^{-7}$ & {$[35]$} \\
\hline Differential pulse voltammetry & $5.0 \times 10^{-6}-50 \times 10^{-6}$ & $3.6 \times 10^{-8}$ & {$[36]$} \\
\hline Differential pulse voltammetry & $2 \times 10^{-7}-1 \times 10^{-6}$ & $2.5 \times 10^{-8}$ & This work \\
\hline
\end{tabular}

Stability and reproducibility

$\mathrm{CV}$ technique was applied to sense the reproducibility of IC $\left(10^{-5} \mathrm{M}\right)$ response at PAMCPE in 0.1 $\mathrm{M}$ PBS, pH 6.0 with the scan rate of $0.1 \mathrm{Vs}^{-1}$. By maintaining the same solution and changing the 
electrode surface at each time, the re-appearance of IC response at PAMCPE is studied for 5 consecutive series. The relative standard deviation (RSD) for reproducibility of anodic peak current response of IC was found to be $2.51 \%$.

In order to detect stability of the electrode towards IC $\left(10^{-5} \mathrm{M}\right)$ sensing, the electrode is made to run for 20 consecutive measurements, Stability can be evaluated by means of percentage degradation method, Eq. (1).

Degradation, $\%=\frac{l_{\mathrm{pn}}}{l_{\mathrm{pl}}} 100$

where, $I_{\mathrm{pn}}$ is peak current of IC during the last CV cycle and $I_{\mathrm{pl}}$ is the peak current of the first CV cycle. Even after $20 \mathrm{CV}$ cycles, it was found that about $84 \%$ of the original current is regained. Both these testing data represent that PAMCPE possesses an outstanding reproducibility and stability towards IC oxidation.

\section{Analytical application of PAMCPE in real sample IC analysis}

In order to assess possible application of the prepared polymer modified electrodes for determination of IC in real water samples, tap water and laboratory waste-water samples were chosen. During this analysis, different concentrations of IC were added to $5 \mathrm{ml}$ water sample and a supporting electrolyte is used to carry out the experiment. Standard addition system was used to identify the quantity and concentration of IC in these samples. The outcome showed that PAMCPE possesses the recovery capacity of the authentic sample in the range of 96.3 to $99 \%$.

To study the applicability of the designed electrode for the presence of IC in a food sample, we selected a candy crush chocolate, purchased from the nearby marketplace. The standard addition method was also adopted to investigate the sample recovery. The recovery ranged from $91.2 \%$ to $99 \%$ for IC. The recovery statistics of the sample represents that the designed electrode is of high sensitiveness and has enormous potential for determination of trace amounts of IC.

\section{Conclusions}

Carbon paste electrode (CPE) was successfully modified with polyarginine, forming PAMCPE electrochemical sensor for indigo carmine (IC) dye. Cyclic and differential pulse voltammetry (CV and DPV) techniques were applied, showing that in comparison with bare CPE, the polymer modified electrode exhibits excellent electrochemical response of IC oxidation. Surfaces of both electrodes were characterized by FESEM. More compact surface structure observed for PAMCPE can be due to the presence of deposited polymer film. Anodic peak current values of PAMCPE presented against IC concentration showed a linear two-slope plot. In the linear region from $2 \times 10^{-7}$ to $10^{-6} \mathrm{M}, \mathrm{LOQ}$ and LOD values were determined as 84.3 and $25.3 \mathrm{nM}$, respectively. Under optimized experimental conditions, CV and DPV measurements of PAMCPE have revealed high sensitivity, selectivity, reproducibility, and reliability towards IC determination. When applied to real water samples (tap) and food stuffs (candy crush chocolate), PAMCPE showed an acceptable outcome. It can be concluded that the designed PAMCPE sensor is easy to prepare, economical, steady, readily renewable and exhibits good catalytic activity towards IC oxidation.

Acknowledgements: We are grateful to acknowledge the financial support from the VGST, Bangalore under the Research Project No. KSTePS/VGST-KFIST (L1) 2016-2017/GRD-559/20172018/126/333, 21/11/2017. 


\section{References}

[1] T. Robinson, G. McMullan, R. Merchant, P. Nigam, Bioresource Technology 77(3) (2001) 247-255 https://doi.org/10.1016/s0960-8524(0,0)00080-8.

[2] J. Hastie, D. Bejan, M. Teutli-León, N. J. Bunce, Industrial \& Engineering Chemistry Research 45 (2006) 4898-4904 https://doi.org/10.1021/ie060310b.

[3] J. J. Berzas-Nevado, J. Rodríguez Flores, M. J. Villaseñor Llerena, N. Rodríguez Fariñas, Talanta 48(4) (1999) 895-903 https://doi.org/10.1016/S0039-9140(98)00301-4.

[4] E. Gutiérrez Segura, M. Solache-Ríos, A. Colín Cruz, Journal of Hazardous Materials 170(2-3) (2009) 1227-1235 https://doi.org/10.1016/i.jhazmat.2009.05.102.

[5] U. R. Lakshmi, V. C. Srivastava, I. D. Mall, D. H. Lataye, Journal of Environmental Management 90(2) (2009) 710-720 https://doi.org/10.1016/i.jenvman.2008.01.002.

[6] K. S. Rowe, K. J. Rowe, The Journal of Pediatrics 125 (1994) 691-698 https://doi.org/10.1016/s00223476(94)70059-1.

[7] E. H. Rodd, Chemistry of carbon compounds, $4^{\text {th }}$ edition, Elsevier, Amsterdam 1960 https://doi.org/10.1002/ange.19600721522.

[8] L. Ge, K. Moor, B. Zhang, Y. He, J. H.-Kim, Nanoscale 6 (2014) 13579-13585 https://doi.org/10.1039/c4nr03647f.

[9] S. Alahiane, S. Qourzal, M. El Ouardi, M. Belmouden, A. Assabbane, Y. Ait-Ichou, Journal of Materials and Environmental Science 4(2) (2013) 239-250.

[10] C. F. Tsai, C. H. Kuo, D. Y.C. Shih, Journal of Food and Drug Analysis 23 (2015) 453-462 https://doi.org/10.1016/j.jfda.2014.09.003.

[11] M. A. Rauf, S. S. Ashraf, Chemical Engineering Journal 151(1-3) (2009) 10-18 https://doi.org/10.1016/j.cej.2009.02.026.

[12] C. L. Jenkins, Journal of Environmental Health 40(5) (1978) 256-263.

[13] R. S. N' Dri, M. Coulibaly, A. N' G. Yao, D. Bamba, E. G. Zoro, International Journal of Electrochemical Science 11 (2016) 5342-5350 https://doi.org/10.20964/2016.06.61.

[14] M. Díaz-González, C. Fernández-Sánchez, A. Costa-García, Analytical Sciences 18(11) (2002) 12091213 https://doi.org/10.2116/analsci.18.1209.

[15] Y. Ni, X. Gong, Analytica Chimica Acta 354(1-3) (1997) 163-171 https://doi.org/10.1016/S00032670(97)00297-3.

[16] E. S. D' Souza, J. G. Manjunatha, C. Raril, T. Girish, D. K. Ravishankar, S. Fattepur, Journal of Materials and Environmental Science 11(3) (2020) 512-521.

https://www.jmaterenvironsci.com/Document/vol11/vol11 N3/JMES-2020-1145-DSouza.pdf

[17] A. H. Alghamdi, Journal of AOAC International 88(5) (2005) 1387-1393 https://doi.org/10.1093/jaoac/88.5.1387.

[18] S. Suzuki, M. Shirao, M. Aizawa, H. Nakazawa, K. Sasa, H. Sasagawa, Journal of Chromatography A 680(2) (1994) 541-547 https://doi.org/10.1016/0021-9673(94)85153-0.

[19] G. M. Greenway, N. Kometa, R. Macrae, Food Chemistry 43(2) (1992) 137-140 https://doi.org/10.1016/0308-8146(92)90227-S.

[20] C.-L. Sun, C.-H. Su, J.-J. Wu, Biosensors and Bioelectronics 67 (2015) 327-333 https://doi.org/10.1016/i.bios.2014.08.046.

[21] I. O. Gyan, I. F. Cheng, Microchemical Journal 122 (2015) 39-44 https://doi.org/10.1016/j.microc.2015.04.002.

[22] D. N. Oko, S. Garbarino, J. Zhang, Z. Xu, M. Chaker, D. Ma, D. Guay, A. C. Tavares, Electrochimica Acta 159 (2015) 174-183 https://doi.org/10.1016/j.electacta.2015.01.192.

[23] D. M. Fernandez, M. Costa, C. Pereira, B. Bachiller-Baeza, I. Rodrígues-Ramos, A. Guerrero-Ruiz, C. Freire, Journal of Colloid and Interface Science 432 (2014) 207-213 https://doi.org/10.1016/j.jcis.2014.06.050.

[24] H. Beitollahi, H. Karimi-Maleh, H. Khabazzadeh, Analytical Chemistry 80 (2008) 9848-9851 https://doi.org/10.1021/ac801854j.

[25] S. Tajik, M. A. Taher, H. Beitollahi, Sensors and Actuators B Chemical 197 (2014) 228-236 https://doi.org/10.1016/j.snb.2014.02.096. 
[26] C. Raril, J. G. Manjunatha, Journal of Materials and Environmental Science 10(6) (2019) 510-519 http://www.jmaterenvironsci.com/Document/vol10/vol10 N6/53-JMES-Raril-2019.pdf.

[27] C. Raril, J.G. Manjunatha, L. Nanjundaswamy, G. Siddaraju, D.K. Ravishankar, S. Fattepur, E. Niranjan, Analytical and Bioanalytical Electrochemistry 10(11) (2018) 1479-1490 https://www.sid.ir/FileServer/JE/55002820181108.pdf.

[28] S. Tajik, H. Beitollahi, F. G. Nejad, M. Safaei, K. Zhang, Q. Van Le, R. S. Varma, H. W. Jang, M. Shokouhimehr, RSC Advances 10 (2020) 21561-21581 https://doi.org/10.1039/d0ra03672b.

[29] G. Tigari, J. G. Manjunatha, D. K. Ravishankar, G. Siddaraju, Methods and Objects of Chemical Analysis 14(4) (2019) 216-223 https://doi.org/10.17721/moca.2019.216-223.

[30] I. Švancara, K. Vytřas, J. Barek, J. Zima, Critical Reviews in Analytical Chemistry 31(4) (2001) 311-345 https://doi.org/10.1080/20014091076785.

[31] J. G. Manjunatha, M. Deraman, N. H. Basri, Asian Journal of Pharmaceutical and Clinical Research 8(5) (2015) 40-45.

[32] Q. Li, J. Yang, X. Tan, Z. Zhang, X. Hu, M. Yang, Luminescence 31 (2016) 1152-1157 https://doi.org/10.1002/bio.3085.

[33] J. J. Berzas, F. J. Rodríguez Flores, M. J. Villaseñor Llerena, N. Rodríguez Fariñas, Analytica Chimica Acta 391(3) (1999) 353-364 https://doi.org/10.1016/S0003-2670(99)00215-9.

[34] J. G. Manjunatha, Journal of Food and Drug Analysis 26 (2018) 292-299 https://doi.org/10.1016/j.jfda.2017.05.002.

[35] P. A. Pushpanjali, J. G. Manjunatha, C. Raril, D. K. Ravishankar, Research Journal of Life Sciences, Bioinformatics, Pharmaceutical and Chemical Sciences 5 (2019) 820-832 https://doi.org/10.26479/2019.0501.68.

[36] N. Hareesha, J. G. Manjunatha, B. M. Amrutha, M. M. Charithra, N. Prinith Subbaiah, Journal of Electronic Materials 50(3) (2021) 1230-1238 https://doi.org/10.1007/s11664-020-08616-7.

(C)2021 by the authors; licensee IAPC, Zagreb, Croatia. This article is an open-access article distributed under the terms and conditions of the Creative Commons Attribution license (https://creativecommons.org/licenses/by/4.0/) 